\title{
Max-min sum minimization transportation problem
}

\author{
Sonia Puri · M. C. Puri
}

Published online: 13 July 2006

(C) Springer Science + Business Media, LLC 2006

Abstract The first-named author would like to go by the name of Sonia.

The Publisher regrets this error.

The online version of the original article can be found at DOI: $10.1007 / \mathrm{s} 10479-006-7387-9$ 